\title{
Health Benefits and Industrial Air Pollution: A Comparison between People's Willingness to Accept and the Opportunity Cost of Health Risk ${ }^{1}$
}

\author{
Wasantha Athukorala ${ }^{2}$
}

\begin{abstract}
The disparity between willingness to accept (WTA) health risks and actual health risks arising from environmental pollution has not been demonstrated well in the literature. This study provides evidence on WTA for bearing existing health risks arising from environmental pollution caused by the Limestone Industry in Sri Lanka. It compares mean WTA with monthly average health expenditure as well as the opportunity cost of health risk. The study finds that the average monthly health expenditure, averting expenditure and lost earning per person were Rs. 168, Rs. 85 and Rs. 262 respectively. Accordingly, opportunity cost of the health damage was Rs. 515 while mean willingness to accept was Rs. 792 per person. Results clearly show that mean WTA estimates tends to overestimate the true cost. The study also summarizes reasons for the disparity and then discusses some of the key implications of the analysis.
\end{abstract}

\section{Introduction}

The effects of air pollution on health are very complex as there are many different sources, and their individual effects vary from one to the other. In order to assess the loss of economic utility associated with the health, one has to use an economic valuation method. This would include expenses such as medical costs and lost income (often referred to as cost of illness), and less tangible effects on well being such as pain, discomfort and restriction of everyday activities. One way of assessing the economic utility loss is to ascertain the individual maximum WTP for the reduced incidence of illness and adverse symptoms (Ayers and Maynard, 2004). The other way of assessing the economic utility loss is to calculate the amount of money for which people are willing to accept (WTA) a certain level of health risk. However, both methods are trying to measure health loss in terms of money.

\footnotetext{
${ }^{1}$ Financial assistance received from American Institute for Sri Lankan Studies for this study is greatly appreciated.

${ }^{2}$ Lecturer, Department of Economics and Statistics, Faculty of Arts, University of Peradeniya, Sri Lanka.

Email: wathukorala@yahoo.com
} 
In welfare economics it is similar to the rate of substitution between health and wealth of the individual (Freeman, 2003; Isik, 2004).

Although WTA has been regarded as the appropriate measure theoretically, in practice, WTP measures are usually used because of the difficulty in getting accurate WTA results ${ }^{3}$ (Pearce and Markandya, 1989; Dubourg et al., 1994). It is often difficult to ask willingness to accept compensation questions in a way that realistically simulates a market. As a result there are only few studies available in the literature that uses WTA method to evaluate risk of air pollution. Hypothetically, WTP estimates can underestimate while WTA can overestimate the reality (Coursey et al., 1987; Hanemann, 1991). Although much theoretical as well as empirical work has been done covering various aspects of WTP there is still a considerable lack of understanding of what difference of the value could be observed between actual situation (cost of illness) and WTA compensation. Against this background, the main objective of this study is to obtain reasonable estimations of peoples' willingness to accept as the compensation for the health risks of industrial air pollution. The specific objectives are (to): compare the discrepancy between willingness to accept compensation and opportunity cost of health risk $^{4}$, and analyze the determinants of WTA compensation. While many economists and policy makers prefer the WTP approach for this type of analysis, there are two reasons for using WTA method in this study. Firstly, from a theoretical perspective, property rights to a clean environment are assumed to belong to the ordinary people and consequently environmental losses should be evaluated using a WTA measure. Secondly, as suggested by Kahneman et al. (1990), individuals value losses more highly than gains, willingness to pay estimates could severely understate value. This means that the real value should be in between WTP and WTA estimations. Our purpose is not to analyze the divergence between WTP and WTA. Instead we analyze the deviation of WTA from opportunity cost of health risk estimates.

\footnotetext{
${ }^{3}$ According to Willig (1976) when it comes to price changes for consumers with well behaved utility functions, the bounds between willingness to pay and willingness to accept were small and the Marshallian consumer surplus lay between these two measures. According to Pearce and Markandya, (1989) willingness to accept measures was of the order of 3 to 20 times greater than willingness to pay measures. After reviewing 45 studies Horowitz and McConnell (2002) revealed that the mean WTA /WTP ratio is 7.17.

${ }^{4}$ Opportunity cost of illness is calculated by adding the cost of medical expenditure, the cost of averting expenditure and the lost earning due to being sick. While this yields only a lower bound to health costs, it is an important starting point.
} 
The paper is organized as follows. The following section provides some of the literature that use CVM method to analyze the health impacts of air pollution in developed as well as developing countries. The theoretical models by laying out the econometric equations and discusses particular elicitation procedures of the contingent valuation methods are presented in the third section. While the fourth section presents the estimation results, the last section presents the main conclusions from our analysis with respect to the design of practical CVM surveys.

\section{Literature Review}

Air pollution has been causing a substantial burden of ill health in many countries (Schwartz, 1994). Costs to a society arising from air pollution include damage to human health, work income lost to illness and the value of the discomfort associated with illness. Of those increased premature mortality and morbidity are generally considered to be the most serious consequences of air pollution in many industrial societies (Ostro, 1994). Therefore it is appropriate to use damage to human health as the primary indicator of the seriousness of air pollution. Krupnick et al. (1990) investigate the daily acute health effects in adults and children associated with daily exposure to ozone and other air pollutants. They find statistically significant and robust effects of ambient ozone concentrations on daily reported respiratory symptoms among healthy non-smoking adults but not among smokers or children.

Schechter and Kim (1991) estimate the valuation of benefits for morbidity reduction associated with air pollution abatement. They use both direct (contingent valuation) and indirect valuation approaches and then proceeds to compare the estimates of welfare changes obtained under these two distinct approaches. Ostro et al. (1993) investigate the acute effects of air pollution in 321 non-smoking adults residing in Southern California. They found a significant association between the incidence of lower respiratory tract symptoms and 1-hour daily maximum ozone levels and ambient sulfates but no association was found with coefficient of haze, a more general measure of particulates. In addition, ozone appears to have had a greater effect among individuals with a pre-existing respiratory infection. Ostro (1994) describes a method for quantifying the benefits of reduced ambient concentrations of pollutants and applies the method to data on Jakarta. According to him the magnitude of the benefits of pollution control depend on the level of air pollution, the expected effects on health of the pollutants (dose-response), the size of the population affected and the economic value of these effects.

Krupnick et al. (1996) estimate the benefits of environmental improvements related to the effects of air pollution on human health in Central and Eastern Europe (CEE). Alberini and Krupnick (1998) analyze the 
daily health status for over 900 residents of three urban areas in Taiwan. They elicit people's willingness to pay to avoid episodes of illness. Alberini and Krupnick (2000) compare cost-of-illness and willingness to pay (WTP) estimates of the damages from minor respiratory symptoms associated with air pollution, using data from a study in Taiwan. According to them WTP is greater than the cost-of-illness estimates depending on pollution levels. It is widely recognized that the cost of illness and averting expenditure provide only a lower bound for the correct measure of willingness to pay (Harrington and Portney, 1987; Alberini and Krupnick, 2000). The few empirical studies have directly queried individuals about their willingness to pay to avoid illness, and have compared willingness-to-pay (WTP), figures with cost-ofillness, (COI), figures. In some studies (Krupnick and Portney, 1991) primarily the costs of productivity loss and health care use are estimated.

Delucchi et al. (2002) compare the estimates of the health and visibility costs of air pollution derived from a meta-hedonic price analysis, with an estimate of health costs derived from a damage-function analysis. According to them the hedonic price analysis does not capture all of the health costs of air pollution because individuals may not be fully aware about all of the health effects.

Meanwhile, various studies undertaken by regulatory agencies and researchers in Sri Lanka have clearly indicated that inefficient and unregulated small-scale industries like limestone, stone-pits and ceramics plants in rural areas are the primary cause of growing air pollution. Lack of information on economic and environmental costs and effects of these damages have impeded the implementation of existing laws and regulations, and the formulation of new regulations in this field. Policy-oriented research in these areas will contribute to a better understanding of the problem and the introduction of effective control measures. However, an extensive literature search revealed no such attempt in Sri Lanka or any other developing countries. Moreover, above literature review reveals that there are a fair number of studies that have measured pollution and personal exposure or health risks. Almost all those studies directly use WTP approach to calculate the value of health benefits. This is one of the principal limitations of the available evidence on the health impact of air pollution exposure in developing countries. In contrast to other approaches this study applies the WTA approach to examine the health risks. 


\section{Research Method and Data}

According to model introduced by Harrington and Portney (1987) an individual's well-being increases with aggregate consumption $(C)$ and leisure $(L)$, but is negatively affected by sick days $(S)$.

$$
U=U\left(C, L, S ; Z_{u}\right)
$$

Where the utility is increasing with $C$ and $L$ while it is decreasing with $S . Z$ is a vector of individual characteristics capturing preferences for income, leisure and health (Alberini and Krupnick, 2000). The relationship between pollution $(P)$ and health outcomes $(S)$ can be summarized into a dose-response function. Assume that health outcomes is a function of pollution level $(P)$ and averting expenditure $(A)$.

$$
\begin{aligned}
& S=S\left(P, A ; Z_{S}\right) \\
& \partial S / \partial A<0 \text { and } \quad \partial S / \partial P>0
\end{aligned}
$$

It is expected that the number of sick days is negatively related with averting expenditure $(A)$ while it is positively related with pollution level $(P)$. Assume that the individual allocate his total time $(T)$ between work $(W)$ and leisure $(L)$ and spend income on aggregate consumption, medical care and averting activities. Individual choose the level of $C, L$ and $A$ to maximize utility subject to the following budget constraint.

$$
\begin{aligned}
& Y+w[T-L-W(S)]=C+P_{m} M(S)+P_{a} A \\
& Y+w T=C+P_{m} M(S)+P_{a} A+w L+w W(S)
\end{aligned}
$$

Where $P_{m}, P_{a}$ are price of medical care $(M)$ and averting activities $(A)$ respectively while $w$ denotes wage rate. The price of a unit of the aggregate consumption good is normalized to one. This budget constraint assumes that individual allocate his time between work and leisure. The left hand side of the equation 3 gives the sum of income earned by working and the value of the leisure while the right hand side of the equation gives the total possible expenditure. ${ }^{5}$ According to the equation three, time allocation to work as well as medical care expenditure is expressed as a function of the number of sick days. Using above simple utility maximization problem Harrington and Portney (1987) and Alberini and Krupnick (2000) decompose the willingness to pay for a small change in pollution as follows.

\footnotetext{
${ }^{5}$ For further details refer Alberini and Krupnick (2000).
} 


$$
W T P=\frac{d S}{d P}\left[w \frac{d W}{d S}+P_{m} \frac{d M}{d S}+P a \frac{d A^{*}}{d S}-\frac{U_{S}}{\lambda}\right]
$$

Equation 5 says that WTP can be expressed as the product of the dose response function $(d S / d P)$ times the marginal value of illness. The term in brackets is the marginal value of illness, broken down into its four main components. Accordingly marginal value of illness is comprised of the values of marginal lost earnings $(d W / d S)$, marginal cost of medical expenditures $(d M / d S)$ and of the marginal cost of the averting activities $(d A / d S)$. In addition WTP includes the disutility of illness $\left(U_{S} / \lambda\right)$, converted into money value through dividing by the marginal utility of income. We use this basic theoretical model, but in slightly different way to assess the willingness to accept to bear the existing pollution level. The information about the level of pollution is not available in that area. As a result we assume that individual WTA is a function of lost earnings, cost of medical expenditures, cost of the averting activities and some household characteristics which includes household income, education level, age, sex, environmental attitudes ${ }^{6}$ and proximity of the house to the industry.

The present study uses Dichotomous-choice method to collect the data. In this approach a sample of individuals receives randomly assigned prices for the compensation to the health damage. After describing possible illness episode in detail, the respondent was asked a valuation question with explaining of his own budget constraint. Each of these questions presented a specific monetary amount and asked whether the respondent was prepared to accept such an amount to entirely avoid this recurrence. For example, the analyst asks the question 'are you willing to accept $X$ amount as the compensation to bearing the existing health risks of the air pollution arising

\footnotetext{
${ }^{6}$ Index is formed by taking weighted average of number of response (statements) by assuming following numerical values: strong positive impact $=2$, positive impact $=1$, no effect $=0$, negative effect $=-1$, strong negative impact $=-2$. By construction, index ranges from -2 to +2 . A positive value implies positive impact, and a negative value implies negative impact. The index was constructed based on following statements: "We have a duty to protect the environment, Everyone has a right to access clean air, We should minimize the damage to the environment now so that out grandchildren may benefit from it, Air pollution can harm for our health, Air pollution in this area is increasing everyday, major reason for pollution is the limestone industry, People who work in this industry do not consider the environment pollution, Government should intervene in every environment problem in this country".
} 
and escalating in this area'. In this method each respondent receives one randomly-drawn price. Respondents are then asked to state whether they would be willing to accept it or not. 'yes' means willing to accept and 'no' means not willing to accept. In this format, respondents are given a 'take it or leave it' offer. The monetary amounts that are presented to respondents are decided from the pilot survey. Accept/reject respondent probability then is calculated for each monetary amount offered (Gunatilake, 2003). The statistical model can be used to estimate a probability of acceptance curve for each identified group within the sample. Yes (1) or no (0) will be used as dependant variable with the bid and other socio-economic determinants of the acceptance/rejection of the bid as the independent variables. Mean Willingness to Accept (MWTA) is calculated by dividing the intercept by the coefficient of the bid level in the estimated Logit regression model. Mathematical derivation of this method is given by Haneman (1991) ${ }^{7}$.

Our data were analyzed using two regression models. In the first regression model we use Logit model to explain the behaviour of the dichotomous dependent variable. As we apply Logit model for individual data, we use a nonlinear estimating procedure based on the method of maximum likelihood. Following Greene (2000) and Gujarati (2003), the Logit model can be generally expressed as

$$
P_{i}=E\left(Y=1 / X_{i}\right)=\frac{1}{1+e^{-Z i}} \quad \text { where } Z_{i}=X_{i} \beta+u_{i}
$$

Where for the $i$ th household, $Y$ is known as the dichotomous variable, $P_{i}$ is the probability of $Y=1$ and $X_{i}$ is a vector of explanatory variables, $u_{i}$ is a random disturbance term, and $\beta$ is a parameter vector common to all households. For estimation purposes we can write the equation 6 as follows.

$$
\mathrm{L}=\operatorname{Ln}\left(\frac{P_{i}}{1-P_{i}}\right)=\mathrm{X}_{\mathrm{i}} \beta+\mathrm{u}_{\mathrm{i}}
$$

\footnotetext{
${ }^{7}$ To understand this, assume that an individual's utility on a commodity, $X$ and left over income that is kept for purchasing environmental goods. Accordingly utility has a deterministic component and a random component $\varphi$ with zero mean. Utility of the individual before answering the CVM question is : $U_{0}=X_{0} \beta+\gamma Y+\varphi_{0}$ If the individual accepts the bid given to him, his utility is: $U_{1}=X_{1} \beta+\gamma(Y+W T A)+\varphi_{1}$, using these two equations, you can get the different of the utility. $U_{0}-U_{l}=\alpha-\gamma W T A$ $+\varphi_{0}-\varphi_{1}$ where $\alpha=X_{0} \beta-X_{1} \beta$. The expected value of this equation: $E\left(U_{0}-U_{1}\right)=E(\alpha)$ - $\gamma E(W T A)$. Individual accept the bid if and only if $U_{l}>U_{0}$ and assume that the individual is indifferent between $U_{0}$ and $U_{l}$, then $\alpha=\gamma E(W T A)$ and $M W T A=\alpha / \gamma$.
} 
The Eviews econometric software package (Version 6) was used to obtain the maximum likelihood estimates for the regression parameters. In the regression model we use the information of all households who accepted the given bid and estimate WPA bid value as a function of some of the explanatory variables using OLS method. The parameters in this model directly give us basic determinate of accepted bid values of household for bearing existing health risk.

The present study is purely based on primary data using survey research technique. A survey was carried out by covering 294 households who live around limestone quarries in Kandy, Matale and Kurunegala in Sri Lanka. The selection of sites for the purpose of extensive survey was carried out using information given by limestone suppliers in these districts. As only few households were located around each site, it is difficult to draw a random sample from the population. In order to maintain a sufficient number of observations, all households who were located one $\mathrm{km}$ distance were selected for the survey. The survey was carried out at household level including individual responses for health status, health expenditure, cultivation, indoor

pollution, bad habits and attitudes on pollution level in the area. In addition to that various socio-economic information and other details such as fuel consumption pattern, cooking behaviour etc. were gathered at the same time. Village officers were consulted to validate data acquired from households and individual level. Data were collected through face-to-face interview of the head of the house along with any helping hands. However, 7 questionnaires had to be dropped out from the analysis as erroneous answers and some outliers were found.

\section{Results and Discussion}

Characteristics of individuals responding to survey are explained below (Table 1). As the survey was carried out only on weekends, the response rate was very high. Average age of the respondents is 42 years with a minimum of 19 and a maximum of 72 years. Male respondents are $76 \%$ while females are $14 \%$. Salaried employment is the main income source of the sample and $68 \%$ is employed either private or government sector. Meanwhile $14 \%$ of the respondents are engaged in various businesses in the area. The mean monthly income of the respondents is Rs. 9,445. The bad habits have a significant influence on the health of people. Our survey data reveals that $37 \%$ of respondents are smoking (cigarette, beedy and suruttu). But of those only 15\% is addicted to smoking. Around 6\% takes alcohol everyday while another $34 \%$ is taking at most 4 days per month. Around $92 \%$ of households have accessed clean water for drinking purpose. It is found that around $74 \%$ of surveyed households use firewood for cooking while another 
$21 \%$ of households use gas for the same purpose. However, some households use gas as well as fire wood for cooking. Most respondents have obtained elementary and secondary education ( $23 \%$ and $72 \%$ respectively).

When considering the environmental damage of the limestone industry in these areas, around $62 \%$ of respondents mentioned that the limestone industry has caused severe deforestation in the $\operatorname{area}^{8}$. However, majority of respondents $(56 \%)$ agree that the air pollution as the most important problem that the government should solve in this area. Almost all households (99\%) believe that Limestone industry is the main reason for that. $31 \%$ of households suggest that the Government must intervene to solve this problem through regulation while $11 \%$ believe that people should get together and get it solved without third party intervention. However, around $40 \%$ have mentioned that they do not have any idea about the solution. Further $94 \%$ and $86 \%$ of respondents are aware that the air pollution causes illness and even death respectively. When we ask whether limestone industry causes damages for their properties, $47 \%$ accepted that this industry causes large damage or minor damage to their properties.

Table 1: $\quad$ Descriptive statistics of the survey data

\begin{tabular}{lrrr}
\hline Variables & Mean & Minimum & Maximum \\
\hline Bid (Rs.) & 530 & 2 & 1000 \\
Income (monthly / Rs.) & 9445 & 2000 & 50000 \\
Medical expenditure (monthly / Rs.) & 168 & 25 & 525 \\
Lost earning (monthly / Rs.) & 262 & 100 & 950 \\
Averting expenditure (monthly / Rs.) & 85 & 13 & 175 \\
Age (years) & 42 & 19 & 72 \\
Family size & 4 & 1 & 9 \\
Environmental Index & 0.65 & -1.88 & 2.0 \\
Proximity (m) & 547 & 20 & 1000 \\
Years of schooling & 8 & 1 & 13 \\
\hline
\end{tabular}

Table 1 shows the summary statistics of the data used for the analysis and the OLS regression. Results show that the average health expenditure was Rs. 168 (month) per person and the average lost earning was Rs. 262 per person. The general information about other variables such as averting expenditure, household income, family size, number of sick days, proximity to the industry and mitigating expenditure can be significant determinants of compensation amount for bearing health risk. Descriptive statistics of those variables are given in Table 1 in order to get a general idea about our sample.

\footnotetext{
${ }^{8}$ Because, almost all industries use fire wood to burn limestone and these fire woods are made by cutting trees in the area.
} 
Figure 1 shows the distribution of responses to offers in the form of a fitted curve. Specific offer amounts are shown on the horizontal axis ranging from the lowest price (Rs. 25) offered to the highest price (Rs. 1,000) offered in 25 increments. The vertical axis measures the percentage of respondents who answered 'yes' to the amount offered. We can interpret the responses in terms of the probability that a randomly drawn member of the sample of respondents is willing to accept a specific amount.

Figure 1: $\quad$ The distribution of the dichotomous choice responses

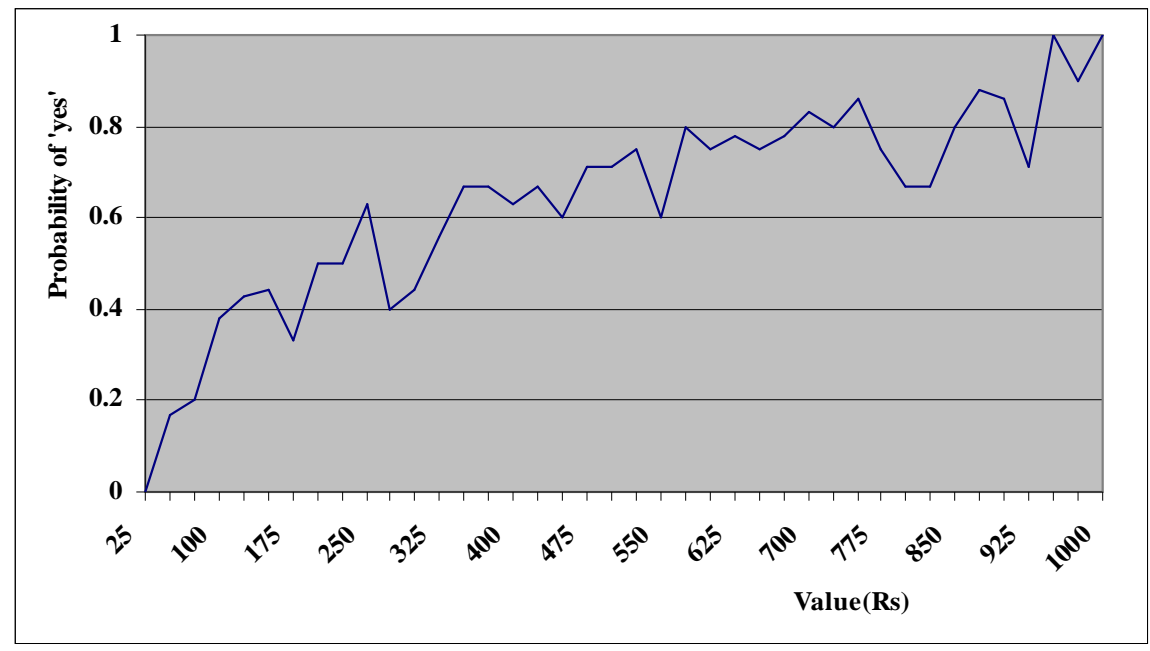

Estimation results of the Logit regression model are shown in Table 2. Each slope coefficient in this equation is a partial slope coefficient and measures the changes in the estimated logit for a unit change in the value of the given regressor, holding other regressor constant. Among the significant variables under different significant level, bid value, medical expenditure, lost of earnings, and years of schooling have positive effects on the logit while income, age and proximity have negative effects on it. It is interesting to observe the negative relationship between WTA and income. Theoretical reason for getting such a result is that when income increases, marginal utility of money can decrease and hence the possibility of accepting of a given bid will be less 9 . The negative sign of the proximity variable confirms that the households residing farther from the limestone industry are less likely to accept compensation as their probability of getting sick is less. Among the

\footnotetext{
${ }^{9}$ However we also may suspect that the survey suffered from inaccurate responses and measurement error in this variable. Some households may hesitate to declare the exact amount of their income in the interviews.
} 
insignificant variables, averting expenditure and environment attitudes are important. However, our observation about the averting expenditure founds that the averting activities are not commonly used in the area. Our descriptive statistics in the Table 1 also shows that average averting expenditure is very small. Insignificant attitude index suggests that willingness to accept for bearing existing health risks was independent from peoples' attitudes about the environment. However, Likelihood ratio test confirms the significance of the included variables collectively. As an alternative method, we use Probit regression method to get the coefficient. We found that there are no much differences of the results ${ }^{10}$.

Table 2: $\quad$ ML Method - Binary Logit Model

\begin{tabular}{|c|c|c|c|c|}
\hline & Coefficient & Std. Error & z-Statistic & Prob. \\
\hline Intercept & $5.5558^{*}$ & 3.5682 & 1.5570 & 0.1195 \\
\hline Bid & $0.0031 * * *$ & 0.0007 & 4.1138 & 0.0000 \\
\hline Income & $-0.8212 * * *$ & 0.2821 & -2.9108 & 0.0036 \\
\hline Medical expenditure & $0.6165^{* * *}$ & 0.2524 & 2.4422 & 0.0146 \\
\hline Loss of Earning & $0.4432 * *$ & 0.2426 & 1.8269 & 0.0677 \\
\hline Averting expenditure & -0.0832 & 0.3533 & -0.2357 & 0.8137 \\
\hline Age & $-0.8926 * *$ & 0.5018 & -1.7786 & 0.0753 \\
\hline Family size & 0.3651 & 0.4163 & 0.8771 & 0.3804 \\
\hline Environment att & 0.0853 & 0.3182 & 0.2683 & 0.7885 \\
\hline Proximity & $-0.4848 * * *$ & 0.1628 & -2.9777 & 0.0029 \\
\hline Years of Schooling & $0.5116^{*}$ & 0.3476 & 1.4718 & 0.1411 \\
\hline Sex ( male 1 , female 0$)$ & -0.0785 & 0.3209 & -0.2446 & 0.8067 \\
\hline \multicolumn{5}{|c|}{ *** Significant under 1 or $5 \%, * *$ Significant under $10 \%, *$ Significant under $15 \%$} \\
\hline McFadden R-squared & 0.2240 & \multicolumn{2}{|c|}{ Mean dependent var } & 0.6457 \\
\hline S.D. dependent var & 0.4791 & \multicolumn{2}{|c|}{ S.E. of regression } & 0.4228 \\
\hline Akaike info criterion & 1.0973 & \multicolumn{2}{|c|}{ Sum squared resid } & 46.3097 \\
\hline Schwarz criterion & 1.2569 & \multicolumn{2}{|l|}{ Log likelihood } & -136.6973 \\
\hline Hannan-Quinn criter. & 1.1614 & \multicolumn{2}{|c|}{ Restr. log likelihood } & -176.1592 \\
\hline LR statistic & 78.923 & \multirow{2}{*}{\multicolumn{2}{|c|}{ Avg. log likelihood }} & -0.5044 \\
\hline Prob(LR statistic) & 0.0000 & & & \\
\hline
\end{tabular}

${ }^{10}$ Estimation results of Probit model are shown in Table 1 in annexure. These parameters reflect the impact of a change in each of the variables on the probability of a 'yes' response. For each household, these parameters define a cumulative distribution function based on the household's characteristics, representing the likelihood that the household is willing to pay a given amount. 
It becomes clear that together all the regressors have a significant impact on the WTA, as the LR statistics is 78.93, whose $\mathrm{p}$ value is equal to zero. Following Haneman (1991) we calculated the Mean Rs. values of WTA. Accordingly the monthly mean willingness to accept was Rs. 792 per person. This represents the average amount of income the household would be willing to accept each month to bear the risk of any household member being sick. The calculated opportunity cost of health damage without including averting expenditure is Rs. $430^{11}$. The result clearly shows that willingness to accept value is much bigger than the opportunity cost of the health damage. When analyzing the qualitative data peoples' expectation about the future possible environmental risk that may be arisen from this industry, peoples' valuation of other environmental damage like deforestation and property damage or property value reduction ${ }^{12}$ are found to be some of the possible reasons of getting higher WTA and hence having a big different between WTA and the opportunity cost of health damage. Although there is no direct quantitative evidence this industry is believed to have caused reduction in visibility, and damages to houses, plants and cultivated crops in the area. When expressing their WTA people can take into account all those factors although those are exogenous to our model.

Table 4: $\quad$ OLS regression Results

\begin{tabular}{lcl}
\hline & Coefficient & P-value \\
\hline Intercept & -100.958 & 0.1529 \\
Medical Expenditure & $0.296^{*}$ & 0.0006 \\
Loss of Earning & $0.198^{*}$ & 0.0001 \\
Averting expenditure & $4.147^{*}$ & 0.0000 \\
Income & $0.007^{*}$ & 0.0001 \\
Proximity to the Industry & $-0.099^{*}$ & 0.0009 \\
Environment attitudes (index) & -2.028 & 0.8561 \\
R-squared & 0.679716 & \\
Adjusted R-squared & 0.666210 & \\
F-statistic & 50.32708 & \\
Prob(F-statistic) & 0.000000 & \\
Log likelihood & -1124.125 & \\
Durbin-Watson stat & 2.036216 & \\
& & \\
\hline
\end{tabular}

* Significant under $1 \%$

${ }^{11}$ As the cost of averting expenditure variable is not significant, we calculated the opportunity cost of health damage by adding the cost of medical expenditure to the lost earning.

${ }^{12}$ Mainly land value has decreased in that area. 
Table 3 shows the determinants of accepted bid values of WTA. The coefficients in the OLS model are interpreted as the marginal impact of the right hand side variable on the dependent variable. Accordingly this result reveals that all variables except environmental attitudes in the WTA function have turned out to be significance. The coefficients of all the variables have expected signs in this equation. Among the five significant parameters correspond to medical expenditure, lost of earning, averting expenditure and income have positively related with accepted bid values while proximity to the industry has a negative sign. According to the OLS results income has shown positive impacts to the accepted WTA bid values.

\section{Conclusion}

This study calculates the amount of money which people are willing to accept (WTA) as compensation for the prevailing level of health risk and compare the MWTA with the opportunity cost of health damage. The dichotomous choice method was used to collect the data covering a sample of 294 households who are living around limestone sites in Sri Lanka. The Logit regression model was run to calculate the mean willingness to accept (MWTA). The study also estimates determinants of household willingness to accept using the OLS method. Results showed that the average monthly health expenditure was Rs. 168 per person. We calculate the opportunity cost of health damage including loss of earning to health expenditure and averting expenditure. It is Rs. 515 per person. We find that the monthly mean willingness to accept for bearing existing health risk as Rs. 792 per person. It clearly shows that the willingness to accept value overestimate the reality, conforming to results from previous studies. However peoples' valuation of exogenous factors including future expectation can have significant impact of making divergence between those two. As a result policy-oriented research covering some of the excluded variables in our model in this field is needed for a better understanding of the problem. We also found that medical expenditure, lost earning, location of the house (proximity) and income are some of the significant determinants of willingness to accept. This general result about the overestimation of WTA drawn from our study follows that of the results of many other contingent valuation studies reported in the literature.

\section{Reference}

Alberini, A. and A. Krupnick (1998). Air Quality and Episodes of Acute Respiratory Illness in Taiwan Cities: Evidence from Survey Data. Journal of Urban Economics, 44(1): 68-92. 
Alberini, A. and A. Krupnick (2000). Cost-of-illness and Willingness-to-pay Estimates of the Benefits of Improved Air Quality: Evidence from Taiwan, Land Economics, 76(1): 37-53.

Ayers, J. and B. Maynard (2004). Air Pollution and Health, London: Imperial College Press.

Coursey, D.L., J.L. Hovis and W.D. Schulze (1987). The Disparity between Willingness to Accept and Willingness to Pay Measures of Value, The Quarterly Journal of Economics, 102(3): 679-690.

Delucchi, M.A., J.J. Murphy and D.R. McCubbin (2002). The Health and Visibility Cost of Air Pollution: A Comparison of Estimation Methods, Journal of Environmental Management, 64: 139-152.

Dubourg, W.R., M.W. Jones-Lee and G. Loomes (1994). Imprecise Preferences and the WTP-WTA Disparity. Journal of Risk and Uncertainty, 9(2): 115-133.

Freeman, A.M. (2003). The Measurement of Environment and Resource Values: Theory and Methods, Washington D.C.: Resources for the Future.

Greene, W.H. (2000). Econometric Analysis, 4th ed. New Jersey: Prentice Hall.

Gujarati, D.N. (2003). Basic econometrics: Forth Edition, Mc Graw Hill.

Gunatilake, H.M. (2003). Environmental Valuation: Theory and Applications. Sri Lanka: Postgraduate Institute of Agriculture.

Hanemann, W.M. (1991). Willingness to Pay and Willingness to Accept: How Much Can They Differ? American Economic Review, 81(3): 635-647.

Harrington, W. and P.R. Portney (1987). Valuing the Benefits of Health and Safety Regulation. Journal of Urban Economics, 22(1): 101-12.

Horowitz, J.K. and K.E. McConnell (2002). A Review of WTA/WTP Studies. Journal of Environmental Economics and Management, 44(3): 426-47. 
Hughes, G. and K. Lvovsky (1998). Addressing the Environmental Costs of Fuels. Paper Presented at the World Congress of Environmental Economists, Venice, Italy.

Isik, M. (2004). Does Uncertainty Affect the Divergence between WTP and WTA Measures? Economics Bulletin, 4(1): 1-7.

Kahneman, D., J. Knetsch and R. Thaler (1990). Experimental Tests of the Endowment Effect and the Coase Theorem, Journal of Political Economy. 98: 1325-1347.

Krupnick, A., V.K. Harrison, E. Nickell and M. Toman (1996). The Value of Health Benefits from Ambient Air Quality Improvements in Central and Eastern Europe: An Exercise in Benefits Transfer, Environmental and Resource Economics, 7(4): 307-332.

Krupnick, A., W. Harrington and B. Ostro (1990). Ambient Ozone and Acute Health Effects: Evidence from Daily Data, Journal of Environmental Economics and Management, 18: 1-18.

Krupnick, A.J. and P.R. Portney (1991). Controlling Urban Air Pollution: A Benefit-cost Assessment. Science, 252: 522-528.

Ostro, B. (1994). Estimating the Health Effects of Air Pollutants : A Method with an Application to Jakarta Policy Research Paper 1301. The World Bank.

Ostro, B., M.J. Lipsett, J.K. Mann, A.J. Krupnick and W. Harrington (1993). Air Pollution and Respiratory Morbidity among Adults in Southern California, American Journal of Epidemiology, 137(7): 691- 700.

Pearce, D.W. and A. Markandya (1989). Environmental Policy Benefits: Monetary Valuation. OECD, Paris.

Schwartz, J. (1994). Air Pollution and Daily Mortality: A Review and Meta Analysis. Environmental Resource, 64(1): 36-52.

Schechter, M. and M. Kim (1991). Valuation of Pollution Abatement Benefits: Direct and Indirect Measurement, Journal of Urban Economics, 30(2): 133-151.

Willig, R. (1976). Consumers Surplus Without Apology, American Economic Review, 66(4): 587-597. 


\section{Annexure}

Table 1: $\quad$ ML Method - Binary Probit Model

\begin{tabular}{|c|c|c|c|c|}
\hline & Coefficient & Std. Error & z-Statistic & Prob. \\
\hline Intercept & $3.301 *$ & 2.186 & 1.510 & 0.131 \\
\hline BID & $0.002 * * *$ & 0.001 & 4.158 & 0.000 \\
\hline Income & $-0.482 * * *$ & 0.169 & -2.858 & 0.004 \\
\hline Medical expenditure & $0.390 * * *$ & 0.142 & 2.745 & 0.006 \\
\hline Lost of Earning & $0.256^{* *}$ & 0.145 & 1.766 & 0.077 \\
\hline Averting expenditure & -0.056 & 0.224 & -0.253 & 0.800 \\
\hline Age & $-0.534 * *$ & 0.286 & -1.863 & 0.062 \\
\hline Family size & 0.177 & 0.229 & 0.773 & 0.439 \\
\hline Environment attitudes (index) & 0.055 & 0.167 & 0.334 & 0.738 \\
\hline Proximity & $-0.289 * * *$ & 0.092 & -3.132 & 0.001 \\
\hline Years of Schooling & $0.286^{*}$ & 0.195 & 1.462 & 0.143 \\
\hline Sex ( male 1 , female 0$)$ & -0.027 & 0.188 & -0.145 & 0.884 \\
\hline \multicolumn{5}{|c|}{ *** Significant under 1 or $5 \%, * *$ Significant under $10 \%, *$ Significant under $15 \%$} \\
\hline McFadden R-squared & 0.227 & \multicolumn{2}{|c|}{ Mean dependent var } & 0.646 \\
\hline S.D. dependent var & 0.479 & \multicolumn{2}{|c|}{ S.E. of regression } & 0.423 \\
\hline Akaike info criterion & 1.093 & \multicolumn{2}{|c|}{ Sum squared resid } & 46.340 \\
\hline Schwarz criterion & 1.252 & \multicolumn{2}{|l|}{ Log likelihood } & -136.156 \\
\hline Hannan-Quinn criter. & 1.157 & \multicolumn{2}{|c|}{ Restr. log likelihood } & -176.159 \\
\hline LR statistic & 80.006 & \multicolumn{2}{|c|}{ Avg. log likelihood } & -0.502 \\
\hline Prob(LR statistic) & 0.000 & & & \\
\hline
\end{tabular}

